\title{
Virus Sars-CoV-2 as a Neuroinvasive Agent
}

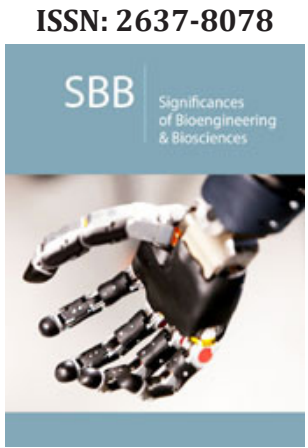

*Corresponding author: Muñetón Gómez VC, Institute of Neurobiology Ramón y Cajal, CSIC, Madrid, Spain andDepartment of Veterinary Medicine, Agricultural Sciences Faculty, Universidad La Salle de Bogotá, Colombia

Submission: 眮 December 22, 2020

Published: 漹January 18, 2021

Volume 4 - Issue 3

How to cite this article: Muñetón Gómez VC, Merino Martín J, Cantó Nogués C, Corrales Cruz A, et al. Virus Sars-CoV-2 as a Neuroinvasive Agent. Significances Bioeng Biosci. 4(3). SBB. 000588. 2021. DOI: 10.31031/SBB.2021.04.000588

Copyright@ Muñetón Gómez VC, This article is distributed under the terms of the Creative Commons Attribution 4.0 International License, which permits unrestricted use and redistribution provided that the original author and source are credited.

\author{
Muñetón Gómez VC ${ }^{1,4 *}$, Merino Martín J², Cantó Nogués $\mathrm{C}^{1}$, Corrales Cruz $\mathrm{A}^{3}$, \\ Muñetón Gómez $C^{4}$, Luna Alcalá $A^{5}$ and Nieto Sampedro M M ${ }^{1,6}$ \\ ${ }^{1}$ Institute of Neurobiology Ramón y Cajal, Spain \\ 2Department of Pharmacology, Pharmacognosy and Botany, Pharmacy Faculty, Universidad \\ Complutense de Madrid, Spain \\ ${ }^{3}$ Intensive Care Unit, Hospital Vithas Internacional Perpetuo Socorro Spain, Spain \\ ${ }^{4}$ Department of Veterinary Medicine, Agricultural Sciences Faculty, Universidad La Salle de \\ Bogotá, Colombia
}

${ }^{5}$ Department of Radiology, Clínica las Nieves HTmedica, Spain

${ }^{6}$ Hospital Nacional de Paraplejicos, Spain

\begin{abstract}
The nervous system is involved in different vital functions that guarantee the survival of the individual. Covid-19 infection is a multisystemic and multi organic disease that disrupts homeostasis and endangers the infected individual's life. It leads to neurological manifestations of varying intensity. However, the nervous system as a target of $\mathrm{CoV}-2$ virus infection must be clarified. In this review we examine the expression of ACE-2 receptor and the interaction of Co-2 virus with nerve cells, describing some findings in nerve cells of different organs. Additionally, a CoV-2 dissemination map is postulated, with emphasis on the nervous functions at the somatic and autonomic levels.
\end{abstract}

Keywords: Virus; COVID 19 disease; Transsynaptic dissemination; Homeostasis; Nervous functions; Somatic; Autonomic nerve; Causative virus

Abbreviations: CNS:Central Nervous System; GFAP: Glial Fibrillary Acidic Protein; NEEC: Neuro Entero Endocrine Cells

\section{Introduction}

Millions of people rambling about the severity of the COVID-19 pandemic have adapted their daily lives to ensure health, stability, livelihoods, and a vital purpose. Reported to the WHO on January 6, 2021, there have been 86,868,467 worldwide confirmed cases of COVID-19, including 1,876,293 deaths. Recovered people are not sure that they have been definitively cured, and that they are immunized against the causative virus. The eventual sequelae include a wide spectrum of physical, psychological and social manifestations, from breathlessness and chronic fatigue to serious conditions such as depression, psychosis, "brain fog" and neurological diseases, among others [1]. Neurological manifestation has been evidenced in COVID-19 [2], however, it is not clear whether the neurological manifestations are due to disturbances in neurological function rather than neurological disease per se. Nervous system injury to COVID-19 has been postulated as mediated by secondary immunity mechanisms [3] rather than a direct CoV-2 neuropathic damage. We review evidence that COVID-19 infection may produce a neurological damage per se through direct infection of neural cells.

\section{The entrance door in the individual}

The CoV-2 enters the body by inhalation of aerosols saliva dropplets from infected people. Some of the first symptoms usually are headache, loss of olfactory discrimination (anosmia) and the lowering of the threshold to flavors, indicative of nervous compromise. The ACE-2 receptor and the transmembrane serine protein TMPRSS2/S4 are the adsorption and entry gate for CoV-2 to cells. These receptors are found in SUS cells, in mucus-producing Horizontal Basal Cells, and in pericytes [4]. CoV-2 have been evidenced in these cells and in sensory neurons of the olfactory epithelium (OSN) by ISH and by IHC detected intracytoplasmic staining for CoV-2 protein within cells of neuronal origin, recognized by antibodies to TuJ1, NF200 and OMP markers. 


\section{Entrance door to the brain}

The presence of SARS-CoV-2 RNA for the virus has been demonstrated in the olfactory bulb and in the olfactory tubercle, a sensory processing center, already housed in the cerebral cortex itself. The viral proteins detected in the respiratory center of the medulla oblongata [5] and the cranial nerves glossopharyngeal (pairs IX) and vagus nerve (pairs X), that converge in the medulla oblongata [6], seem to be responsible for the autonomic disfunction and problems with breathing, cardiac arrhythmia and abnormal blood gas levels, that contribute to the need of assisted ventilation in seriously infected patients [7].

\section{Transsynaptic pathway brain dissemination}

Taking advantage of the polarization of neurons and the machinery responsible for anterograde (from the soma) and retrograde (towards the soma) transport, $\mathrm{CoV}-2$ and virions travel by neural circuits through synaptic clefts [8]. Infected neural cells were evidenced near the olfactory bulb, in brain structures such as the frontal lobe [9], thalamus [5], basal ganglia, brainstem, cerebellum, hippocampus [6] and midbrain [10]. The infected structures include activated microglial cells, the innate antigen presenting cells (APC) of the. central nervous system (CNS). This is evidenced by the expression of MHC-1: histocompatibility HLA-DR antigen, the lectin IBa1 and the protein TMEM119. The presence of reactive astrocytes is evidenced by their morphological change and their overexpressing glial fibrillary acidic protein (GFAP). The activation of the acquired immune response is evidenced by the presence of cytotoxic, CD8 positive lymphocytes [6].

\section{Brain dissemination by disruption of the blood-brain- barrier}

Vascular pericytes express high levels of ACE-2 receptors and are infected by CoV-2 [4]. Electron microscopy permits visualizing cells of the vascular epithelium with basement membrane and the formation of shoots with virions fusing with the neuronal membrane. This fusion is postulated to induce the production of molecules with a chemoattractant effect for effector cells, such as macrophages [9] that affect BBB permeability. Vasogenic edema, due to the passage of fluid from the intravascular to the extracellular space, is common in the white matter. Extravasation hemorrhage and vessels with increased perimetral space are also evidenced. Histopathology and confocal microscopy images show blood vessels and brain thrombi infested by CoV-2 viruses [11].

\section{Spinal cord infection}

Most of somatic and autonomic nerve endings in tissues (Peripheral Nervous System) are communicated with ganglia, which are groups of neurons outside the CNS. Their axons communicate at various metameric levels with the spinal cord $[12,13]$ reaching the brain in an organized or somatotopic manner. ACE- 2 receptor is expressed in the spinal cord and angiotensin, a neuropeptide involved in nociception [14]. It is postulated that CoV-2 uses this pathway to infect sensory neurons of the anterior horn and motor neurons of the ventral horn [15].

\section{Infection of the gut neural environment}

The throat is a reservoir of $\mathrm{CoV}-2$. The swallowed virus evades digestive defense mechanisms and invade the digestive tract and intestine. CoV-2 may gain access to the CNS through the glossopharyngeal and vagus nerve. The terminals of the vagus nerve are located along oral and gastrointestinal tracts and afferents to intramural neuronal cells are grouped mainly in two plexuses: the submucosal and the myenteric. Neuronal plexuses expressing ACE-2 receptor and markers such as PGP 9.5 and HuC of intermediate filaments of the neuronal cytoskeleton [16] may be targets for CoV-2 invasion. On the other hand, based on single-cell transcriptomic analysis, ACE2 and TMPRSS2 are also co expressed in both upper epithelial and gland cells from esophagus and absorptive enterocytes from ileum and colon [17]. In the intestine, neuroenteroendocrine cells (NEEC) emit projections to the lumen of the intestine and interact with microbiota and mucus. These local nerve cells produce classic neurotransmitters, neuropeptides and neurohormones, stored separately in different subcellular compartments [18] that are targeted by the CoV2 virus. The electron microscopy shows hair cells with ultrastructural features compatible with NEEC, infected by CoV-2, and virions released from the villi into the intestinal lumen. Goblet cells are not infected. The virus is excreted with the feces [19].

\section{Conclusion}

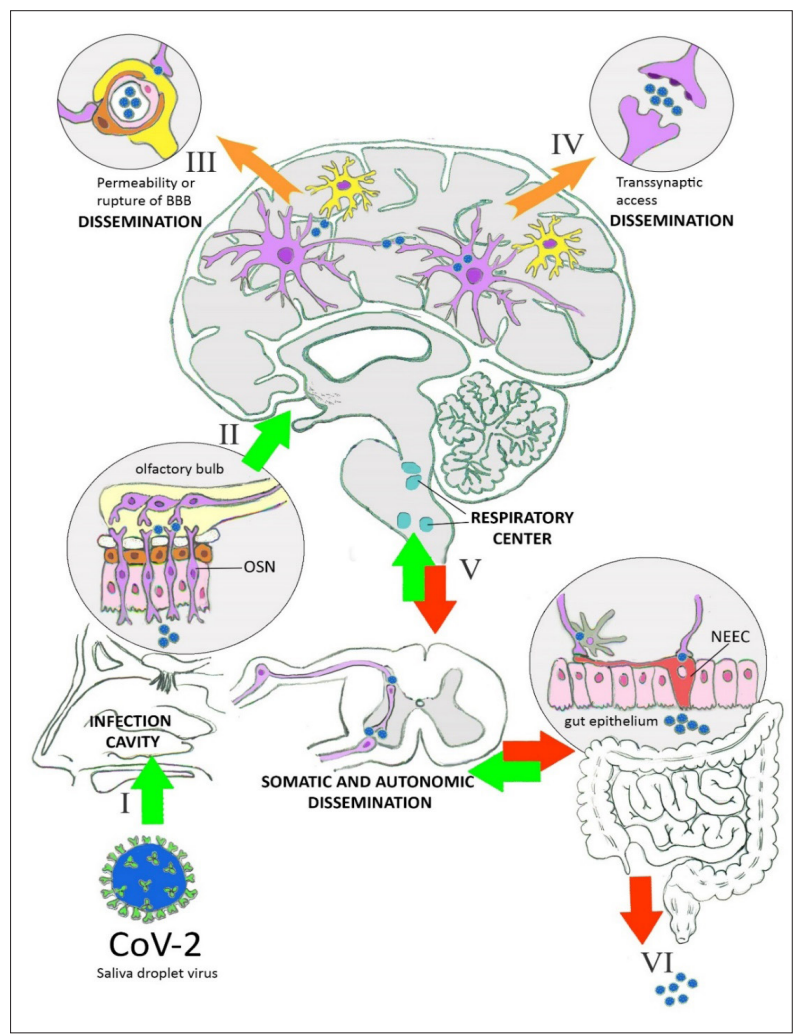

Figure 1: A pathway for neuronal dissemination of CoV-2 through the neural environment is postulated in COVID-19 disease, including some of the most affected organs. 
Sars-CoV-2 has been detected in human neural cells on autopsy by in situ hybridization, IHC, RT-PCR and lesions have been evidenced by radiological TC and RMN. Infected cells included neurons of the olfactory system, brainstem, hippocampus, motor and sensory spinal cord, gut and diffuse glia as astrocytes, oligodendrocytes and Schwann cells. The causative agent of COVID-19 is a neuroinvasive and neurovirulent agent, that infects neurons of the CNS and PNS even in the absence or low expression of serine protease and ACE2 receptors. Glial cells have a protagonist role in the mechanisms of response to $\mathrm{CoV}-2$ infection. We have described a pathway for dissemination of CoV-2 infection through the CNS (Figure 1) and some of the most affected organs in COVID-19 disease. Neuropathic damage can involve direct infection of nerve cells in the tissue microenvironment.

\section{References}

1. Davis N (2020) Sheer fear: Mental health impacts of Covid-19 come to fore Cases of PTSD, anxiety, depression and insomnia lead to calls for routine follow-up of survivors. The Guardian's science correspondent. Published on Fri 14 Aug 2020.

2. Paterson RW, Brown RL, Benjamin L, Nortley R, Wiethoff S, et al. (2020) The emerging spectrum of COVID-19 neurology: clinical, radiological and laboratory findings. Brain 143(10): 3104-3120.

3. Doncel-Pérez E, Contreras M, Gómez-Hernando C, Vargas-Baquero E, Blanco-García JB, et al. (2020) What is the impact of the antibody response to glycan alpha-gal in guillain-barré syndrome associated with SARS-CoV-2 infection? Merit Research Journal of Medicine and Medical Sciences 8(11): 730-737.

4. Brann DH, Tsukahara T, Weinreb C, Lipovsek M, Van den Berge K, et al. (2020) Non-neuronal expression of SARS-CoV-2 entry genes in the olfactory system suggests mechanisms underlying COVID19-associated anosmia. Sci Adv 6(31): 1-19.

5. Meinhardt J, Radke J, Dittmayer C, Franz J, Thomas C, et al. (2020) Olfactory transmucosal SARS-CoV-2 invasion as a port of central nervous system entry in individuals with COVID-19. Nature Neuroscience 1-13.

6. Matskchke J, Lütgehetmann M, Hagel C, Sperhake JP, Sophie Schröder A, et al. (2020) Neuropathology of patients with COVID-19 in Germany: A post-mortem case series. Lancet Neurol 2020 19(11): 919-929.

7. Baig AM (2020) Neurological manifestations in COVID-19 caused by SARS-CoV-2. CNS Neuroscience and Therapeutics 26(5): 499-501.
8. Dubé M, Coupanec AL, Wong HMA, Rini JM, Desforges M, et al. (2018) Axonal transport enables neuron-to-neuron propagation of human coronavirus 0C43. J Virol pp. 1-54.

9. Mondolfi AP, Bryce C, Grimes Z, Gordon RE, Reidy J, et al. (2020) Central nervous system involvement by severe acute respiratory syndrome coronavirus-2 (SARS-CoV-2). J Med Virology 92(7): 699-702.

10. Jacob F, Pather SR, Huang WK, Zhang F, Wong SZH, et al. (2020) Human Pluripotent stem cell-derived neural cells and brain organoids reveal sars-cov-2 neurotropism predominates in choroid plexus epithelium. Cell Stem Cell 27(6): 937-950.

11. Magro CM, Mulvey J, Kubiak J, Mikhail S, Suster D, et al. (2020) Severe COVID-19: A multifaceted viral vasculopathy syndrome. Ann Diagn Pathol 13: 50.

12. Muñetón-Gómez V, Averill S, King V, Yang Q Doncel-Pérez E, et al. (2003) Transplantation of olfactory ensheathing cells fails to promote significant axonal regeneration from dorsal roots into the rat cervical cord. J Neurocytol 32(1): 53-70.

13. Muñetón-Gómez V, Taylor JS, Averill S, Priestley JV, Nieto-Sampedro M (2004) Degeneration of primary afferent terminals following brachial plexus extensive avulsion injury in rats. Biomédica 24(2): 183-193.

14. Nemoto WA, Nakagawasai O, Yaoita F, Kanno SI, Yomogida S, et al. (2013) Angiotensin II produces nociceptive behavior through spinal AT1 receptor-mediated p38 mitogen-activated protein kinase activation in mice. Molecular Pain 2013 9: 38.

15. Jacomy H, Talbot PJ (2003) Vacuolating encephalitis in mice infected by human coronavirus OC43. J Virology 315(1): 20-33.

16. Deffner F, Scharr M, Klingenstein S, Klingenstein M, Milazzo A, et al. (2020) Histological evidence for the enteric nervous system and the choroid plexus as alternative routes of neuroinvasion by SARS-CoV2. Front Neuroanat 14: 596439.

17. Zhang H, Kang Z, Gong H, Xu D, Wang J, et al. (2020) Digestive system is a potential route of COVID-19: an analysis of single-cell coexpression pattern of key proteins in viral entry process. Gut 69(6): 1010-1018.

18. Ye L, Liddle RA (2017) Gastrointestinal hormones and the gut connectome. Curr Opin Endocrinol Diabetes Obes 24(1): 9-14.

19. Lamers MM, Joep Beumer, Vaart J, Knoops K, Puschhof J, et al. (2020) SARS-CoV-2 productively infects human gut enterocytes. Science 369(6499): 50-54. 